\title{
Technical considerations for ligation of ruptured hepatic artery aneurysm: is arterial reconstruction necessary?
}

\author{
S Lam *, Albert CY Chan, Ronnie TP Poon
}

\section{A B S T R A C T}

Ruptured hepatic artery aneurysm is a rare lifethreatening condition. Open surgery with ligation of the aneurysm is the treatment of choice if the patient presents with haemodynamic instability. Controversies exist on whether hepatic artery reconstruction is needed after exclusion of the aneurysm. Involvement of the gastroduodenal artery origin was proposed as an indication for reconstruction, but this might be difficult to ascertain upon laparotomy. Recent studies showed that arterial ligation distal to the gastroduodenal artery origin does not necessarily result in ischaemic liver injury, implying that reconstruction in such cases may not be required, especially in a haemodynamically unstable patient. A patient with common hepatic artery aneurysm involving the gastroduodenal artery origin presented with rupture and underwent aneurysm ligation. Adequacy of intrahepatic arterial flow was determined by intra-operative Doppler ultrasonography and arterial reconstruction was not performed. The technical considerations during the operative management of ruptured hepatic artery aneurysms are discussed.

\section{Hong Kong Med J 2015;21:276-9 DOI: $10.12809 / \mathrm{hkmj} 144260$}

${ }^{1}$ S Lam *, MB, BS, MRes (Med)

${ }^{2}$ ACY Chan, FRCS (Edin), FCSHK

${ }^{2}$ RTP Poon, FRCS (Edin), FCSHK

Department of Surgery, Queen Mary Hospital, Pokfulam, Hong Kong

2 Department of Surgery, The University of Hong Kong, Pokfulam, Hong Kong

* Corresponding author: lamshi07@gmail.com

\section{Introduction}

Hepatic artery aneurysm (HAA) is an uncommon condition that can present with life-threatening haemorrhage. In case of catastrophic intraperitoneal rupture, laparotomy with ligation of the aneurysm is often the treatment of choice due to its rapid access and ability to secure control of the extravasation site. Controversy exists whether hepatic artery should be reconstructed after ligation of the aneurysm, especially when distal ligation is performed on the hepatic artery proper. We herein describe the technical considerations during the operative management of a patient with ruptured HAA.

\section{Case report}

A 69-year-old male presented to Queen Mary Hospital, Hong Kong, with a 3-week history of epigastric pain in December 2010. A contrastenhanced computed tomography (CT) of the abdomen showed a common HAA with involvement of the root of gastroduodenal artery (GDA; Fig 1a) but there was no evidence of contrast leakage or haematoma formation at the time of diagnosis. Complete blood profile showed evidence of inflammation that included mild leukocytosis with neutrophil predominance, thrombocytosis, and mildly elevated erythrocyte sedimentation rate.
Serum biochemistry showed elevated $\gamma$-glutamyl transpeptidase and C-reactive protein. Screening for vasculitis and infection was unremarkable.

Three days later, however, the patient developed generalised peritonitis complicated by hypovolaemic shock during the workup for this condition in the hospital. There was an acute drop in haemoglobin level from $150 \mathrm{~g} / \mathrm{L}$ to $125 \mathrm{~g} / \mathrm{L}$. A diagnosis of rupture of the common HAA was made clinically and an emergency laparotomy was performed.

On entering the peritoneal cavity, $5 \mathrm{~L}$ of hemoperitoneum was recovered, and after fourquadrant packing of the peritoneal cavity, supracoeliac aortic clamping was performed to secure temporary haemostasis. The lesser sac was entered and a ruptured $4 \times 3 \mathrm{~cm}$ fusiform aneurysm of the common hepatic artery surrounded by inflamed tissues cranial to the pancreatic head region was identified. The proximal and distal neck of the aneurysm was subsequently isolated and encircled by tape without further dissection at the hepatoduodenal ligament. After release of the aortic clamp, the distal neck of the aneurysm at the hepatic artery proper was test clamped and Doppler ultrasonography was performed, which confirmed good biphasic flow in both the right and left hepatic arteries. The aneurysm was then ligated and suture-transfixed at its proximal and distal neck region (Fig 2). 
In the postoperative period, the alanine and aspartate transaminase levels were elevated to $1607 \mathrm{U} / \mathrm{L}$ and >3000 U/L, respectively. Both the liver parenchymal enzymes returned to normal levels 3 weeks after the procedure. A short course of renal replacement therapy was required for the acute renal injury sustained during the shock. Otherwise, the patient made an uneventful recovery. Pathological examination of the aneurysm wall showed infiltration of lymphocytes and neutrophils but there was no evidence of infection.

Follow-up CT performed at 2 and 8 months postoperatively showed arterial collateral formation along the porta hepatis, and there was no evidence of previous liver infarction (Figs $1 \mathrm{~b}$ and 1c).

\section{Discussion}

Hepatic artery aneurysm is a rare condition with an estimated prevalence of $0.1 \%$ according to autopsy series, ${ }^{1}$ and incidence of $0.002 \%{ }^{2}$ The majority (75\%) of cases are incidentally diagnosed, and pain in the right upper quadrant or epigastrium is the most common presenting symptom. ${ }^{1}$ Rupture is the second most common mode of presentation and accounts for $14 \%$ of the newly diagnosed HAAs. ${ }^{2}$

The reported mortality rate for ruptured HAA is $21 \%$ to $43 \%,^{2,3}$ and the key to successful resuscitation is timely control of the ruptured site. Although endovascular exclusion of HAAs has a reported success rate of up to $100 \%,{ }^{4}$ open surgery is often the treatment of choice if the exsanguinating haemorrhage does not permit a failed trial of endoluminal haemostasis.

The objectives of open surgery are to exclude the diseased artery segment and preserve the hepatic arterial inflow. It is generally accepted that aneurysms of the common hepatic artery which do

\section{肝動脈瘤破裂結紮術的技術因素：有必要進行 動脈重建嗎? \\ 林需、陳智仁、潘冬平}

肝動脈瘤破裂十分罕見, 一旦破裂後死亡率很高。如果病人血運情況 不穩定, 一般會進行瘤體結紮術。問題是移除動脈瘤後, 是否需進行 血管重建? 這仍然存在爭議。有説假如動脈瘤源自胃十二指腸動脈, 便須進行肝動脈重建, 可是在剖腹時很難斷定。最近的研究顯示離胃 十二指腸動脈較遠的動脈結紮並不一定會造成缺血性肝損傷, 意味在 這種情況下可能無需進行血管重建, 尤其是在血運情況不穩定的病人 中。本文報告一名患有肝動脈瘤破裂並牽涉胃十二指腸動脈的病人, 為他進行瘤體結紮。術中多普勒超聲檢查確定病人的肝動脈無血運障 礙, 所以沒有為病人進行血管重建。本文續討論處理肝動脈瘤破裂手 術時所需考慮的技術因素

not involve the GDA can be simply ligated without reconstruction of inflow to the hepatic artery proper because the latter is supplied by the reverse flow from the GDA. ${ }^{5}$ For aneurysms involving GDA or distal to its origin, the conventional advocate is to reconstruct hepatic arterial inflow after ligation or resection of the aneurysm to avoid the risk of ischaemic injury to the liver. ${ }^{6}$ Depending on the morphology and size of the aneurysm, inflow restoration may take the form of aneurysmectomy with patch graft repair or exclusion of aneurysm with coeliac or aorto-hepatic bypass grafting. Autogenous saphenous vein is the preferred graft, although a dacron prosthetic graft can also be used. ${ }^{6}$ In our patient, because of the clinical suspicion of an infective aetiology for the ruptured aneurysm and
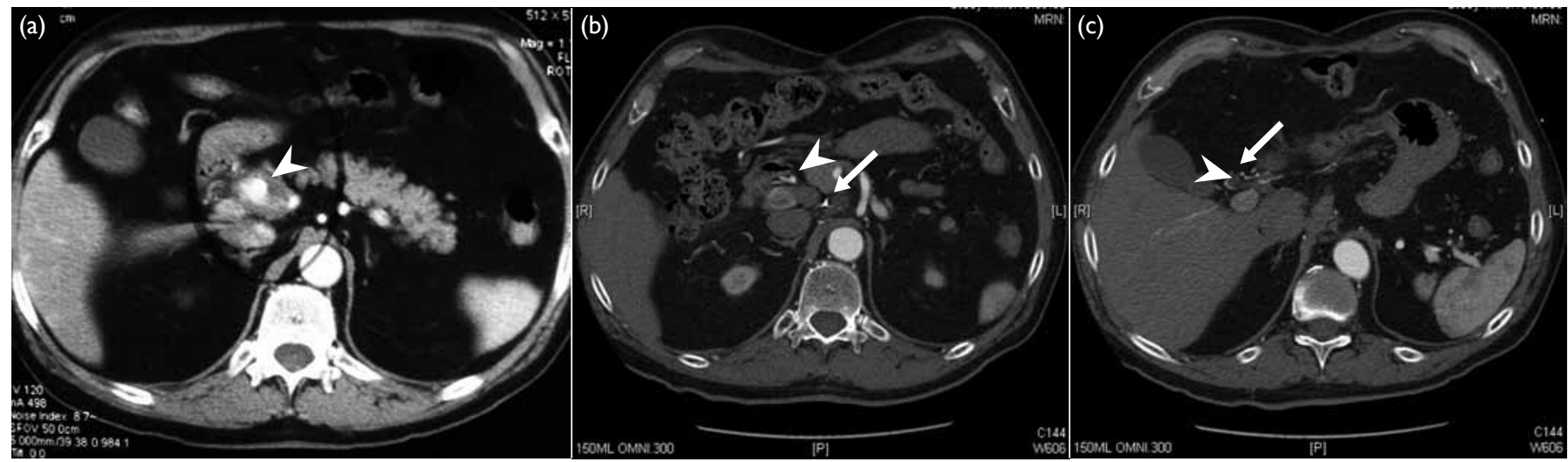

FIG I. Computed tomography images

(a) Preoperative scan showing an aneurysm involving the gastroduodenal artery (arrowhead); (b) 2-month postoperative surgical clip marks the site of proximal neck ligation of common hepatic artery (arrow); the gastroduodenal artery (arrowhead) is discontinuous from the hepatic artery proper; (c) 8-month postoperative pericholedochal collateral vessels (arrow) along the common bile duct (arrowhead) 


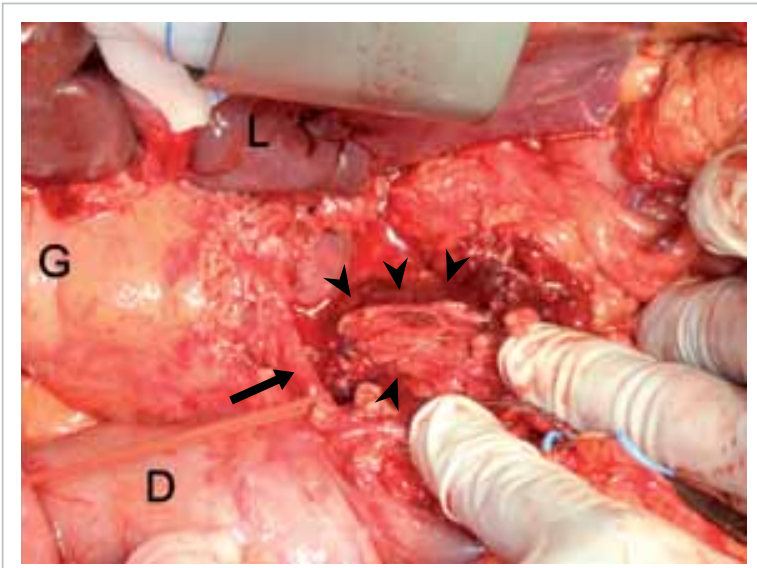

FIG 2. Intra-operative photo showing the liver (L), gallbladder $(G)$, duodenum (D), hepatic artery proper (arrow) and the laid-open common hepatic artery aneurysm sac (arrowheads) after distal ligation (sutures)

due to the satisfactory hepatic arterial flow during intra-operative ultrasound, arterial reconstruction was not considered.

Graham and $\mathrm{Cannel}^{7}$ had reviewed that accidental hepatic artery ligation would result in greater than $50 \%$ mortality when the site of ligation is distal to the GDA. In later studies, however, such a high mortality rate was not observed with hepatic artery ligation during iatrogenic injuries or therapeutic procedures to 'de-arterialise' tumourladen livers. ${ }^{5,8,9}$ It is believed that the liver is protected from ischaemic insults after hepatic artery ligation by a buffer response of the portal venous system. The portal vein maintains the supply of $70 \%$ of hepatic inflow and $50 \%$ of hepatic oxygen consumption during acute hepatic artery interruption, before compensatory arterial supply develops. ${ }^{6} \mathrm{With}$ time, a multitude of arterial collateral channels can develop to compensate for the interruption of original arterial inflow. In fact, postoperative CT scan at 8 months in our patient clearly showed collateral formation via the pericholedochal route (Fig 1c). Besides, Michels ${ }^{10}$ has described 26 potential sites of collateral arterial supplies to the liver originating from the celiac trunk, superior mesenteric artery and intrathoracic arteries, routing via the hepatoduodenal ligament, hepatogastric ligament, omentum, retroperitoneum, falciform ligament, and diaphragmatic connections. Collateral formation is observed after ligation of hepatic arteries in angiographic studies as early as 10 hours after ligation. ${ }^{5}$ Moreover, replaced or accessory arterial supplies to the left or right hepatic lobes are present in about $30 \%$ of the general population, ${ }^{5,11}$ rendering feasible supply to the contralateral lobe via the interlobar anastomosis at the liver hilum. The clinical relevance of such vascular recovery potential was demonstrated by Chirica et al, ${ }^{12}$ wherein the technique of simple aneurysm ligation with minimal dissection in the hepatoduodenal ligament was adopted so as to preserve the potential arterial collaterals and hence avoiding the need for reconstruction of the extirpated hepatic artery in three out of four patients in their series of HAAs with GDA involvement.

Establishment of arterial collaterals, however, is a latent process and the anatomical information on the presence of aberrant or replaced hepatic arterial supply may not be readily available at the time of laparotomy for a ruptured aneurysm. In this situation, intra-operative Doppler ultrasonography is a convenient tool for evaluation of intrahepatic arterial flow. In transplanted livers, a normal Doppler waveform of the hepatic artery includes a rapid upstroke with an acceleration time of $<80 \mathrm{~ms}$, a continuous diastolic flow giving a resistive index between 0.5 and 0.7 , and a peak systolic velocity of $<2 \mathrm{~m} / \mathrm{s}$; any deviation from normality from any of these parameters is suggestive of hepatic artery stenosis and predictive of subsequent ischaemic bile duct injury. ${ }^{13}$ Perhaps, the same criteria can be adopted to assess the arterial sufficiency in a native liver. Back bleed from distal cut end of hepatic artery and cyanosis of hepatic lobe should be counted with caution as these have been reported to be inaccurate in predicting adequate perfusion or subsequent ischaemic injury, respectively. ${ }^{14}$

\section{Conclusion}

Simple ligation of the hepatic artery is considered safe and effective in the treatment of ruptured HAA. The establishment of arterial collaterals should be expected given that the hepatoduodenal ligament is not severely disrupted. The use of intra-operative ultrasound facilitates the decision-making in devising the operative strategy for this condition.

\section{Declaration}

No conflict of interest was declared by the authors.

\section{References}

1. Arneson MA, Smith RS. Ruptured hepatic artery aneurysm: case report and review of literature. Ann Vasc Surg 2005;19:540-5.

2. Abbas MA, Fowl RJ, Stone WM, et al. Hepatic artery aneurysm: factors that predict complications. J Vasc Surg 2003;38:41-5.

3. Shanley CJ, Shah NL, Messina LM. Common splanchnic artery aneurysms: splenic, hepatic, and celiac. Ann Vasc Surg 1996;10:315-22.

4. Tulsyan N, Kashyap VS, Greenberg RK, et al. The endovascular management of visceral artery aneurysms and pseudoaneurysms. J Vasc Surg 2007;45:276-83.

5. Mays ET, Wheeler CS. Demonstration of collateral arterial flow after interruption of hepatic arteries in man. $\mathrm{N}$ Engl J 
Med 1974;290:993-6.

6. Tygstrup N, Winkler $\mathrm{K}$, Mellemgaard $\mathrm{K}$, Andreassen $M$. Determination of the hepatic arterial blood flow and oxygen supply in man by clamping the hepatic artery during surgery. J Clin Invest 1962;41:447-54.

7. Graham RR, Cannel D. Accidental ligation of the hepatic artery. Br J Surg 1933;20:566-79.

8. Ariyan S, Cahow CE, Greene FL, Stansel HC Jr. Successful treatment of hepatic artery aneurysm with erosion into the common duct. Ann Surg 1975;182:169-72.

9. Brittain RS, Marchioro TL, Hermann G, Waddell WR, Starzl TE. Accidental hepatic artery ligation in humans. Am J Surg 1964;107:822-32.

10. Michels NA. Collateral arterial pathways to the liver after ligation of the hepatic artery and removal of the celiac axis.
Cancer 1953;6:708-24.

11. Covey AM, Brody LA, Maluccio MA, Getrajdman GI, Brown KT. Variant hepatic arterial anatomy revisited: digital subtraction angiography performed in 600 patients. Radiology 2002;224:542-7.

12. Chirica M, Alkofer B, Sauvanet A, Vullierme MP, Levy Y, Belghiti J. Hepatic artery ligation: a simple and safe technique to treat extrahepatic aneurysms of the hepatic artery. Am J Surg 2008;196:333-8.

13. Crossin JD, Muradali D, Wilson SR. US of liver transplants: normal and abnormal. Radiographics 2003;23:1093-114.

14. Mathisen DJ, Athanasoulis CA, Malt RA. Preservation of arterial flow to the liver: goal in treatment of extrahepatic and post-traumatic intrahepatic aneurysms of the hepatic artery. Ann Surg 1982;196:400-11. 